\title{
Cardioprotective Activity of Flavonoid Fraction of Gymnema Sylvestre Leaves on Doxorubicin Induced Cardiac Damage
}

\author{
Bhupalam Pradeepkumar*1, Akkiraju Sudheer ${ }^{1}$, Talla Srinath Reddy' ${ }^{1}$, Kanala Somasekhar Reddy ${ }^{1}$, Goruntla Narayana ${ }^{2}$, Kasturi Veerab- \\ hadrappa ${ }^{3}$ \\ 'Department of Pharmacology, ${ }^{2}$ Department of Pharmacy Practice, ${ }^{3}$ Department of Pharmacognosy, Raghavendra Institute of Pharmaceutical Education and Research \\ (RIPER), KR Palli Cross, Chiyyedu Post, Ananthapuramu, Andhra Pradesh, INDIA.
}

\begin{abstract}
Objective: The objective of this study is to evaluate the Cardioprotective activity of flavonoid fraction of Gymnema Sy/vestre leaves on doxorubicin induced cardiac damage in rats. Method: The rats were divided into four groups as normal control, doxorubicin control, standard and test with six rats in each group. Cardiotoxicity was induced in all groups of animals except in normal control by single intraperitoneal injection of doxorubicin (15 mg/kg, i.p.). $24 \mathrm{~h}$ after the last treatment, the effects were evaluated by using serum biomarkers, lipid profile, tissue antioxidants, and histopathological examination. Serum and tissue homogenate parameters were measured by semi-auto analyzer and spectrophotometer, respectively. The results obtained were assessed by one-way analysis of variance followed by Bonferroni test. Results: The flavonoid fraction pretreatment significantly attenuated the levels of pathological biochemical markers like creatine kinase-MB (CK-MB), lactate dehydrogenase (LDH), serum glutamic oxaloacetic transaminase (SGOT), total cholesterol, triglycerides, uric acid, calcium, nitric oxide and melanoldehyde, and significantly raises the levels of endogenous protective antioxidant proteins in the doxorubicin-intoxicated rats. In the test group, pre-treatment with flavonoid fraction isolated from
\end{abstract}

the leaves of Gymnema Sylvestre normalized the activity of cell membrane bound ATPases. A histopathological finding in the flavonoid fraction pretreated rats reveals that it has prevented the pathological changes observed with doxorubicin intoxication. Conclusion: Pre-treatment of rats with the flavonoid fraction of Gymnema Sylvestre significantly ameliorated the toxic insult perpetrated by doxorubicin.

Key words: Cardiotoxicity, Doxorubicin, Flavonoid fraction, Gymnema Sylvestre.

\section{Correspondence}

Dr. Bhupalam Pradeepkumar, Associate Professor and Head, Dept. of Pharmacy Practice, Raghavendra Institute of Pharmaceutical Education and Research (RIPER), KR Palli Cross, Chiyyedu Post, Ananthapuramu, Andhra Pradesh, INDIA.

Phone: +919985968504

Email: bhupalampradeep@gmail.com

DOI: 10.5530/jyp.2018.10.93

\section{INTRODUCTION}

Cancer chemotherapy produces multiple organ damage that includes kidney, heart, liver, hematological and lymphoid system. Management of cancer chemotherapy induced toxicity is also challenging for researchers. ${ }^{1}$ Doxorubicin (DOX) is an anthracycline antibiotic which is used for multiple cancers like solid tumors as well as hematological cancers in children and adults. ${ }^{2}$ But doxorubicin treatment for a long duration as well as dose-dependent causes cardiotoxicity. Acute cardiotoxicity develops in short span of treatment which is characterized by various arrhythmias, cardiomegaly and ultimately heart failure. The latter two effect ranges from specific heart failure symptoms to lethal left ventricular failure. ${ }^{3}$ Pathogenesis of doxorubicin induced cardiotoxicity are multifactorial and involve in generation of iron-dependent free radicals which damage nucleic acids and thus progress to cardiomyocyte apoptosis, calcium overload, sodium overload, and of activation of apoptotic activators like TNF- $\alpha$ and nuclear factor-kappa B. ${ }^{4}$ Approaches in tackling this unavoidable situation include dose reduction, use of liposomal formulation, shift to another less toxic drugs or use of cardioprotectives like $\beta$-blockers, ACE inhibitors, ARBs, dexrazoxane, statins, amifostine, phenyl butyrate, and glutathione. ${ }^{5}$ Among above approaches, preventive use of cardioprotective with dexrazoxane is clinically more popular. Dexrazoxane again creates secondary cancers and oppose the effect of anticancer drugs. At this junction a major challenge for researcher is to explore the new cardioprotective agents with good therapeutic profile and concomitantly do not effect activity of anticancer compounds. ${ }^{6}$ Among several approaches lessening the free radical generation and associated cardiotoxicity with use of natural antioxidants is the one of the best and most sought after approach. Previously several researchers have tried and succeeded at preclinical level by using natural products with antioxidant activity like naringenin, probucol, resveratrol, epigallocatechin gallate and quercetin against doxorubicin induced cardiotoxicity. ${ }^{7}$ Gymnema Sylvestre (Asclepiadaceae) is popular as antidiabetic herb in Indian ayurvedic system of medicine. The phytoconstituents responsible for these effects include triterpenes, gymnemic acids, gymnemasaponins, and a polypeptide, gurmarin.$^{8-9}$ It is also accepted for treatment of arthritis, osteoporosis, hypercholesterolemia, cardiomyopathy, asthma, constipation, microbial infections, indigestion, and inflammation. ${ }^{10}$ The main motto of the present work was to screen the flavonoid rich portion isolated from Gymnema Sylvestre leaves for cardioprotective activity in doxorubicin cardiotoxicity model.

\section{MATERIALS AND METHODS}

\section{Ethical approval}

A preclinical pharmacological screening for Cardioprotective activity of flavonoid fraction of Gymnema Sylvestre leaves on doxorubicin induced cardiac damage in rats was performed after clear approval from Insti-

This is an open access article distributed under the terms of the Creative Commons Attribution-NonCommercial-ShareAlike 4.0 License, which allows others to remix, tweak, and build upon the work non-commercially, as long as the author is credited and the new creations are licensed under the identical terms. 
tutional Animal Ethical Committee (IAEC) with an approval number: 878/ac/05/CPCSEA/009/2012. The guidelines of the Committee for the Purpose of Control and Supervision of Experiments on Animals (CPCSEA), Ministry of Social Justice and Empowerment, Government of India, were followed throughout the study.

\section{Chemicals}

All chemicals used were of analytical grade and purchased from standard companies such as Doxorubicin injection from Kunal Pharma, Secunderabad. Adenosine triphosphate, Vitamin-E, trichloro acetic acid, thiobarbituric acid and Ellman's reagent were purchased from Hi-Meda Pvt. Ltd., Mumbai.

\section{Collection and identification of plant material}

The leaves of Gymnema Sylvestre were collected from the Nallamala forest region, Tirupati, Andhra Pradesh. The plant material was authenticated and identified by Dr. J. Raveendra Reddy, JNTUA, Anantapur, where the voucher specimen was (RIPER- 08/12) deposited for further reference.

\section{Extraction and Isolation of Flavonoid fraction from Gymnema Sylvestre leaves}

$250 \mathrm{gm}$ of plant powder was treated with hexane and macerated in $1000 \mathrm{~mL}$ of absolute methanol for $72 \mathrm{~h}$. After filtration, the filtrate was evaporated by using a rotary evaporator at the temperature not exceeding $45^{\circ} \mathrm{C}$ to give a residual to which hot water was added $(200 \mathrm{~mL})$. After $5 \mathrm{~h}$ of agitation, the aqueous filtrate follows the solvent /solvent extraction with chloroform, ethyl acetate, and $n$-butanol. To the lower aqueous layer, anhydrous sodium sulfate was added to separate the flavonoid-rich fraction and subjected to filtration. The filtrate was evaporated to get the residue. The obtained $5.9 \mathrm{gm}$ residua were stored at $2-8^{\circ} \mathrm{C} .{ }^{11}$

\section{Phytochemical screening of flavonoid fraction}

The isolated flavonoid fraction was identified by chemical tests and thin layer chromatography (TLC).

\section{TLC study}

The isolated flavonoid fraction was identified by TLC by using toluene: chloroform: methanol as mobile phase at a ratio of 4:4:1 v/v/v followed by detecting the chromatogram using UV chamber at $365 \mathrm{~nm}$ green fluorescent.

\section{Experimental Animals}

Male Wistar rats weighing 150-200 g body weight were procured from the Raghavendra Enterprises, Bangalore, Karnataka. India. The animals were housed in polypropylene cages at $22 \pm 1{ }^{\circ} \mathrm{C}$, relative humidity $55 \pm 5 \%$, and $12 \mathrm{~h} / 12 \mathrm{~h}$ light-dark cycle. Animals were kept at the central animal house of the institute and provided with normal pellet diet and drinking water was given ad libitum. The rats were divided into four groups of six animals each, and acclimatized to the laboratory atmosphere for a minimum of seven days prior to the study and were used only once throughout the experiment.

\section{Experimental design and protocol}

The animals were divided into four different groups of six animals each. Group I and Group II were received 0.5\% CMC suspension at the dose of $1 \mathrm{~mL} / 200 \mathrm{~g}$, p.o. termed as normal control and doxorubicin control, respectively; Group III (Test) received $100 \mathrm{mg} / \mathrm{kg}$, p.o. of Gymnema Sylvestre flavonoid fraction (GSFF). Group IV (Standard) received Vitamin-E $100 \mathrm{mg} / \mathrm{kg}$ suspended in 0.5\% CMC, p.o. ${ }^{12}$ All treatments were continued for 10 days by the oral route. Except for Group I, all the other groups were subjected to doxorubicin toxicity with the dose of $15 \mathrm{mg} / \mathrm{kg}$, i.p. on the $7^{\text {th }}$ day. ${ }^{13}$

\section{Estimation of Biochemical parameters in the serum}

On the $11^{\text {th }}$ day, under light ether anesthesia, blood samples were drawn by retro-orbital puncture into Eppendorf tubes and allowed to clot. The clotted blood was centrifuged at $3000 \mathrm{RPM}$ for $15 \mathrm{~min}$. Carefully taken out the serum and kept on $-80^{\circ} \mathrm{C}$ for the estimation of creatine kinase-MB (CK-MB), lactate dehydrogenase (LDH), serum glutamic oxaloacetic transaminase (SGOT), total cholesterol, triglycerides, uric acid and serum nitric oxide by using commercial kits with the help of semi-auto analyzer (Aruba). ${ }^{14}$

After phlebotomy, animals were sacrificed under pentobarbital sodium (35 mg/kg, i.p.) anesthesia. Three hearts from each group were immediately isolated, washed with ice-cold phosphate-buffered saline $(\mathrm{pH}=7.4)$, blotted, and subjected to freezing at $-80^{\circ} \mathrm{C}$ until further use. A small section of the myocardial tissue from each group was fixed at $10 \%$ neutral buffered formalin solution for histopathological examination.

\section{Estimation of Myocardial tissue parameters}

Isolated hearts were homogenized in $100 \mathrm{~mm}$ Tris- $\mathrm{HCl}$ (pH 7.4) using Homogenizer (Remi) at $0^{\circ} \mathrm{C}$ and centrifuged at 10000 RPM by using Remi C-24 high speed cooling centrifuge. Decanted supernatant was utilized for the estimation of reduced glutathione (GSH), catalase (CAT), superoxide dismutase (SOD) lipid peroxidation (LPO) and thiobarbituric acid reactive substances (TBARS). After decantation, the remaining portion was used for measurement of the activity of membrane-bound ATPases and calcium content. ${ }^{15}$

\section{Histopathological study}

Heart sections were prepared from the remaining three rats of each group. The processed tissue sections were embedded in paraffin, cut to the $5 \mu \mathrm{m}$ section for slides, and stained with hematoxylin and eosin. The slides were examined with a Magnus microscope. The sections were observed under 40X magnification. Observations were performed by an individual blinded to the treatments.

\section{Statistical analysis}

All the data were expressed as mean \pm SEM. Statistical significance between more than two groups was tested using one-way analysis of variance (ANOVA) followed by the Bonferroni test using Graph Pad Prism 3.0 software (San Diego, California, USA). $P<0.05$ was considered statistically significant.

\section{RESULTS}

\section{Phytochemical investigation of flavonoid}

Preliminary phytochemical screening of the flavonoid fraction of Gymnema Sylvestre leaves showed positive reaction towards test for flavonoids. Results of Preliminary phytochemical screening of the flavonoid fraction of Gymnema Sylvestre leaves were noted in Table 1. Further, TLC was also performed in which $R f$ values of the flavonoid fraction were found to be $0.64,0.75$ and 0.78 .

\section{Effect of pre-treatment of GSFF on serum cardiac marker enzymes and transaminase levels}

Serum levels of cardiac marker enzymes such as CK-MB, LDH $(P<0.001)$ and transaminases such as SGOT $(P<0.05)$ were significantly higher in the doxorubicin control group as compared with the normal control group. Rats pretreated with GSFF shows decreased levels of serum cardiac marker enzymes such as CK-MB $(P<0.001)$, LDH $(P<0.01)$ and 
Table 1: Preliminary phytochemical screening of flavonoid fraction of Gymnema Sylvestre leaves.

\begin{tabular}{cc}
\hline Test & Inference \\
\hline Shinoda test & + \\
Alkaline test & + \\
Lead acetate test & + \\
Sulphuric acid test & + \\
Ferric chloride test & + \\
\hline
\end{tabular}

Table 2: Effect of GSFF on doxorubicin induced alterations on serum biochemical parameters (Creatinine Kinase -MB, lactate dehydrogenase, and SGOT).

\begin{tabular}{cccc}
\hline Group & CK-MB (IU/L) & LDH (IU/L) & SGOT(IU/L) \\
\hline Normal control & $131.4 \pm 3.29$ & $187.5 \pm 7.127$ & $34.63 \pm 2.50$ \\
Doxorubicin Control & $342.0 \pm 11.72 \mathrm{a}$ & $760.2 \pm 26.48 \mathrm{a}$ & $102.5 \pm 5.28 \mathrm{c}$ \\
Test & $261.3 \pm 6.23 \mathrm{a}$ & $665.1 \pm 19.22 \mathrm{~b}$ & $66.29 \pm 6.20 \mathrm{c}$ \\
Standard & $180.8 \pm 4.18 \mathrm{a}$ & $358.1 \pm 12.64 \mathrm{a}$ & $65.28 \pm 5.03 \mathrm{c}$ \\
\hline
\end{tabular}

All values are presented as mean $\pm \operatorname{SEM}(\mathrm{n}=6) . P<0.001$ is denoted by a, $P<0.01$ is denoted by $\mathrm{b}$ and $P<0.05$ is denoted by $\mathrm{c}$.

SGOT $(P<0.05)$ as compared with doxorubicin control group as shown in Table 2.

\section{Effect of pre-treatment of GSFF on serum biochemical parameters}

Serum levels of other biochemical parameters such as uric acid $(P<0.01)$, total cholesterol $(P<0.05)$ and triglycerides $(P<0.01)$ were significantly increased in the doxorubicin control group as compared with the normal control group. Rats pretreated with GSFF shows significantly decreased
Table 3: Effect of GSFF on doxorubicin induced alterations on serum biochemical parameters (Uric acid, Total cholesterol, Triglycerides).

\begin{tabular}{cccc}
\hline Group & $\begin{array}{c}\text { Uric acid } \\
(\mathrm{mg} / \mathrm{dL})\end{array}$ & $\begin{array}{c}\text { Total } \\
\text { Cholesterol } \\
(\mathrm{mg} / \mathrm{dL})\end{array}$ & $\begin{array}{c}\text { Triglycerides } \\
(\mathrm{mg} / \mathrm{dL})\end{array}$ \\
\hline $\begin{array}{c}\text { Normal control } \\
\text { Doxorubicin control }\end{array}$ & $1.51 \pm 0.15$ & $21.45 \pm 0.63$ & $27.66 \pm 1.35$ \\
Test & $1.66 \pm 0.19 \mathrm{~b}$ & $44.10 \pm 8.44 \mathrm{c}$ & $66.95 \pm 4.04 \mathrm{~b}$ \\
Standard & $1.67 \pm 0.3 \mathrm{~b}$ & $20.74 \pm 0.69 \mathrm{c}$ & $41.68 \pm 3.06 \mathrm{c}$ \\
\hline
\end{tabular}

All values are presented as mean \pm SEM $(n=6)$. $P<0.001$ is denoted by a, $\mathrm{P}<0.01$ is denoted by $\mathrm{b}$ and $\mathrm{P}<0.05$ is denoted by $\mathrm{c}$.

levels of uric acid $(P<0.01)$, total cholesterol $(P<0.05)$ and triglycerides $(P<0.05)$ as compared with doxorubicin control group as shown in Table 3.

\section{Effect of pre-treatment of GSFF on cardiac tissue endogenous antioxidant systems}

Doxorubicin control group exhibit marked the elevation of lipid peroxidation and reduction of endogenous catalase, superoxide dismutase, and glutathione was observed as compared to a normal control group. Amelioration of doxorubicin-induced oxidative stress was observed with GSFF pretreatment, this was confirmed by significant reduction of LPO $(P<0.01)$ and significant elevation of CAT $(P<0.05)$, SOD $(P<0.01)$ and GSH $(P<0.01)$ as compared with doxorubicin control group. Changes of antioxidant parameters in cardiac tissue were shown in Table 4.

\section{Effect of pre-treatment of GSFF on membrane bound ATPase enzymes}

Doxorubicin control group showed marked reduction of activity of $\mathrm{Na}^{+} / \mathrm{K}^{+}$ATPase and $\mathrm{Mg}^{++}$ATPase as compared to a normal control group. Restoration of activity of these enzymes by the GSFF pretreatment

Table 4: Effect of GSFF on oxidative parameters in heart tissue homogenate.

\begin{tabular}{ccccc}
\hline Group & SOD & $\begin{array}{c}\text { CAT } \\
\text { (Umoles } \mathrm{H}_{2} \mathrm{O}_{2} \\
\text { decomposed } \\
\text { mg protein/ min) }\end{array}$ & $\begin{array}{c}\text { GSH } \\
\text { (nmoles of GSH/mg } \\
\text { protein) }\end{array}$ & $\begin{array}{c}\text { LPO } \\
\text { (nmoles of MDA/ mg } \\
\text { protein) }\end{array}$ \\
\hline $\begin{array}{c}\text { Normal control Doxorubicin } \\
\text { control }\end{array}$ & $23.12 \pm 0.47$ & $21.41 \pm 2.18$ & $18.29 \pm 0.94$ & $9.02 \pm 0.59$ \\
Test & $9.70 \pm 1.03 \mathrm{~b}$ & $8.17 \pm 0.5 \mathrm{c}$ & $5.09 \pm 0.57 \mathrm{~b}$ & $32.90 \pm 2.36 \mathrm{~b}$ \\
Standard & $24.38 \pm 1.26 \mathrm{~b}$ & $22.63 \pm 0.49 \mathrm{c}$ & $13.93 \pm 0.57 \mathrm{~b}$ & $12.86 \pm 0.59 \mathrm{~b}$ \\
\hline
\end{tabular}

All values are presented as mean $\pm \operatorname{SEM}(\mathrm{n}=6) . P<0.001$ is denoted by a, $P<0.01$ is denoted by $\mathrm{b}$ and $P<0.05$ is denoted by $\mathrm{c}$.

Table 5: Effect of GSFF on cardiac membrane bound enzymes.

\begin{tabular}{ccc}
\hline Group & $\begin{array}{c}\text { Na+/ K+ ATPase } \\
(\mu \mathrm{M} \text { of inorganic } \mathrm{pi} \\
\text { liberated/mg protein/ } \\
\mathbf{m i n} .)\end{array}$ & $\begin{array}{c}\text { Mg++ ATPase } \\
(\mu \mathrm{M} \text { of inorganic } \mathrm{pi} \\
\text { liberated/mg protein/ } \\
\mathrm{min})\end{array}$ \\
\hline Normal control & $121.3 \pm 1$ & $63.82 \pm 0.44$ \\
Doxorubicin control & $112.8 \pm 0.16 \mathrm{c}$ & $40.97 \pm 3.53 \mathrm{c}$ \\
Test & $128.9 \pm 1.21 \mathrm{~b}$ & $56.77 \pm 2.62 \mathrm{c}$ \\
Standard & $130.8 \pm 1.10 \mathrm{c}$ & $60.09 \pm 1.0 \mathrm{c}$
\end{tabular}

All values are presented as mean $\pm \operatorname{SEM}(n=6)$. $\mathrm{P}<0.001$ is denoted by a, $\mathrm{P}<0.01$ is denoted by $\mathrm{b}$ and $\mathrm{P}<0.05$ is denoted by $\mathrm{c}$.
Table 6: Effect of GSFF Ca ${ }^{++}$levels in Heart tissue homogenate and plasma nitric oxide level.

\begin{tabular}{ccc}
\hline Group & $\begin{array}{c}\text { Heart tissue Calcium } \\
\text { levels } \\
\text { (Nano moles/mg } \\
\text { protein) }\end{array}$ & $\begin{array}{c}\text { Plasma nitric oxide } \\
\text { levels }(\mu \mathrm{M})\end{array}$ \\
\hline Normal control & $10.81 \pm 0.68$ & $8.550 \pm 0.53$ \\
Doxorubicin control & $20.69 \pm 1.2 \mathrm{a}$ & $17.77 \pm 0.64 \mathrm{a}$ \\
Test & $15.04 \pm 0.8 \mathrm{~b}$ & $12.60 \pm 0.78 \mathrm{a}$ \\
Standard & $11.39 \pm 1.12 \mathrm{a}$ & $14.87 \pm 0.56 \mathrm{c}$ \\
\hline
\end{tabular}

All values are presented as mean $\pm \operatorname{SEM}(n=6) . P<0.001$ is denoted by a, $\mathrm{P}<0.01$ is denoted by $\mathrm{b}$ and $\mathrm{P}<0.05$ is denoted by $\mathrm{c}$. 
was observed as compared to doxorubicin control group $(P<0.01$ and $P<0.05)$ as shown in Table 5.

\section{Effect of pre-treatment of GSFF on $\mathrm{Ca}^{++}$levels in heart tissue homogenate and nitric oxide level in plasma}

Doxorubicin control group showed significantly elevated levels of calcium level in heart tissue and plasma nitric oxide levels as compared to a normal control group. GSFF pretreated rats exhibit the normalized levels as compared to doxorubicin control group $(P<0.001$ and $P<0.01)$ as shown in Table 6.

\section{Effect of Pre-treatment of GSFF on Histopathological examination of cardiac tissue}

Effect of GSFF Pre-treatment with doxorubicin-induced histopathological changes in rat cardiac tissue depicted in Figure 1. Doxorubicin intoxicated rats demonstrated with the recruitment of more leukocytes infiltration with cellular edema and inflammation. GSFF pre-treated rats demonstrated normal cardiac muscle fibers with no signs of focal necrosis with lower inflammatory cells infiltration and morphology of cardiac muscle was relatively preserved with only slight hemorrhage.

\section{DISCUSSION}

The present study was undertaken to evaluate the cardioprotective activity of Gymnema Sylvestre flavonoid fractions against doxorubicin induced cardiotoxicity. Cardiospecific enzymes are generally present very low levels in serum. When the membrane disrupts theses enzymes like $\mathrm{CK}-\mathrm{MB}$ and $\mathrm{LDH}$ leak out into the plasma and rise in appreciable
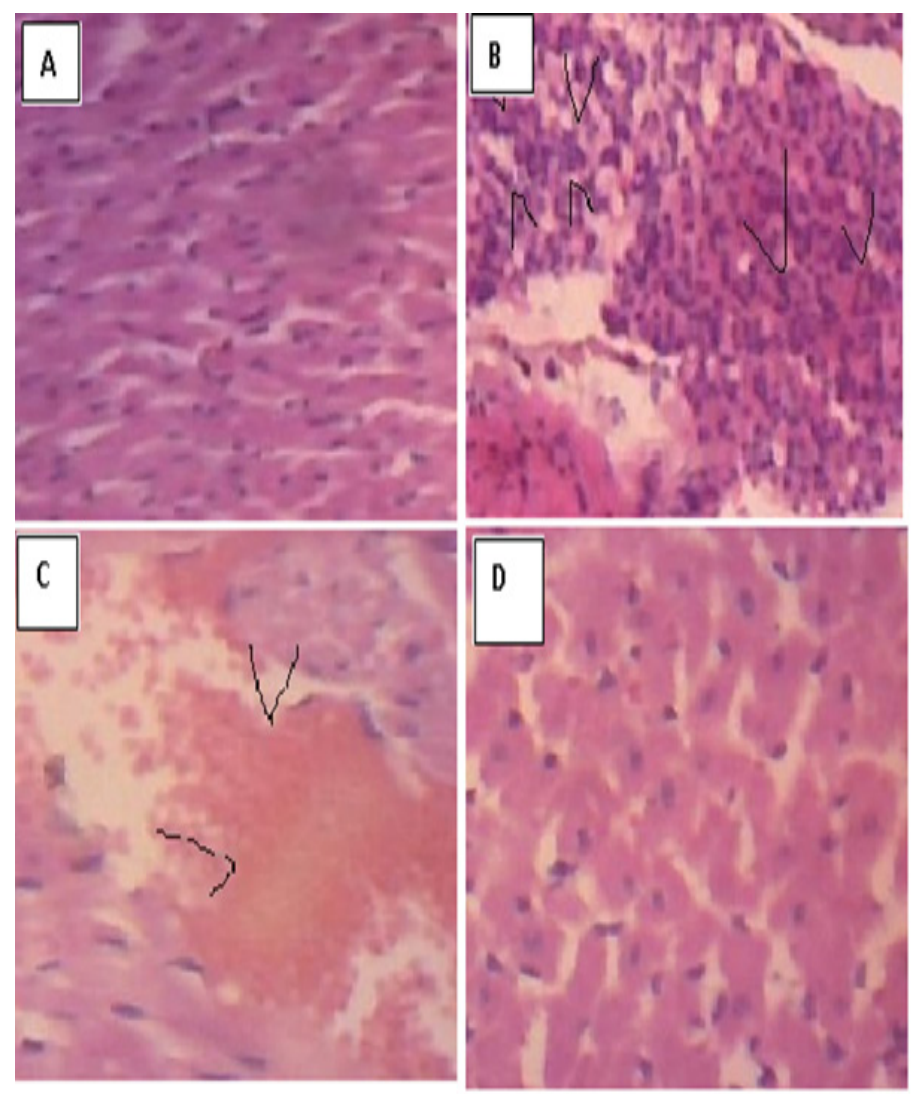

Figure 1: Effect of doxorubicin induced cardiotoxicity on histopathological alterations and its amelioration by GSFF in rat hearts (40x representative photomicrographs). A. Normal control; B. Doxorubicin control; C. Test; D. Standard.. quantities, which gives information about the extent of myocardial damage due to lipid peroxidation. ${ }^{16}$ Results of the present study significantly demonstrated a rise in the serum levels of LDH and CK-MB after doxorubicin administration. Treatment with flavonoids fraction of Gymnema Sylvestre significantly reduced the serum levels of $\mathrm{LDH}$ and CK-MB. It is hypothesized that decreased permeability of membrane as a result of protection from oxidative damage was responsible for this effect. The endogenous antioxidant system efficiently neutralizes reactive oxygen species (ROS) such as superoxide anion, hydroxyl radical, hydrogen peroxide, and nitric oxide. When the balance between ROS and antioxidant is disrupted, ROS accumulate and produce various pathological changes in body tissues which ultimately contribute as causative factors for many diseases as in the case of cardiovascular diseases..$^{17}$ Doxorubicin enhances the free radical formation and decreases antioxidant enzymes due to overwhelming consumption of antioxidants which can lead to cardiac failure. ${ }^{18}$ Similar findings were observed in the present study where decreased levels of SOD, CAT, GSH and increase in MDA (marker of lipid peroxidation) levels were observed in the cardiac tissue following doxorubicin administration. After treatment with the flavonoid fraction, the cellular antioxidant levels were normalized and MDA levels were found to be reduced significantly. These findings suggest that the flavonoid fraction of Gymnema Sylvestre protects the myocardium due to its antioxidant activity.

Smooth endoplasmic reticulum maintains the optimal level of intracellular calcium for myocardial contraction but as oxidative stress increases there is a decrease in contractility and a concurrent activation of caspase-12 induced apoptosis. ${ }^{19}$ In hypoxic tissues, purines are released from damaged nucleic acids and finally degraded to uric acid by the xanthine oxidase enzyme system. The same reaction also releases additional superoxide radical as a by-product. This is the reason for elevated levels of serum uric acid in DOX-injected rats. Administration of GSFF showed significant improvement in serum uric acid level. This might be due to the prevention of oxidative damage of nucleic acids..$^{20}$ Doxorubicin generated free radicals, especially $\mathrm{H}_{2} \mathrm{O}_{2}$, activates NOS synthase which further evokes synthesis of $\mathrm{NO}$ and reactive oxygen species such as superoxide. Furthermore, these two radicals can react together, leading to the synthesis of peroxynitrite $\left(\mathrm{ONOO}^{-}\right)$, a powerful cellular oxidant molecule, which may be an important contributor to doxorubicininduced cardiac dysfunction. Doxorubicin administration increases the plasma levels of nitric oxide by this mechanism.

Administration of GSFF showed a significant decrease in the serum levels of NO. This might be due to neutralization of DOX generated free radicals. ${ }^{21}$ Increase in lipid parameters like total cholesterol and triglycerides was observed in the DOX-treated group while pretreatment with GSFF showed a reduction in total cholesterol and triglycerides due to the presence of bioactive compound like flavonoids that prevent elevation in cholesterol and triglyceride levels. ${ }^{22}$ Membrane bound ATPases were involved in the energy-dependent movement of $\mathrm{Na}^{+}$, $\mathrm{Ca}^{2+}$ and $\mathrm{Mg}^{2+}$ ions across the cell membrane of the cardiac cell. This transport plays a significant role in contraction and relaxation cycles of cardiac muscles. Membrane bound ATPase functions were altered by loss of sulfhydryl (-SH) groups and membrane lipid peroxidation during oxidative stress. DOX administration showed significant fall in activity of membrane bound enzymes. Cytosolic calcium accumulation may be a relevant mechanism leading to cell death and had been proposed to play an important role in the pathogenesis of lethal myocardial cellular injury. The restoration of membrane bound enzymes like $\mathrm{Na}^{+} / \mathrm{K}^{+}$ATPase, $\mathrm{Mg}^{+}$ ATPase and intracellular calcium levels in GSFF-treated rats was indicative of membrane stabilizing the protective effect of GSFF. ${ }^{23}$

As seen in the present study, DOX treatment caused significant histological changes including marked infiltration of inflammatory cells, myofibril 
loss, and cytoplasmic vacuolization. ${ }^{24}$ In rat treated with GSFF, these DOX-induced histological changes were minimal, suggesting protection from cellular damage by GSFF.

\section{CONCLUSION}

Based on the results of the present study, it was concluded that pre-treatment of rats with the flavonoid fraction of Gymnema Sylvestre significantly ameliorated the toxic insult perpetrated by doxorubicin. Thus, use of this fraction can find clinical application for management of doxorubicin-induced cardiotoxicity in patients undergoing doxorubicin chemotherapy.

\section{CONFLICT OF INTEREST}

The authors declare no conflict of interest.

\section{ACKNOWLEDGEMENT}

The authors were grateful to the management and principal of Raghavendra Institute of Pharmaceutical Education and Research (RIPER) for their constant support, encouragement and providing necessary facilities for this research work.

\section{ABBREVIATIONS}

GSFF: Flavonoid fraction of Gymnema Sylvestre leaves; DOX: Doxorubicin; CK-MB: Creatine kinase-MB; LDH: Lactate dehydrogenase; NO: Nitric oxide; CAT: Catalase; SGOT: Serum glutamic oxaloacetic transaminase; SOD: Superoxide dismutase; GSH: Glutathione

\section{REFERENCES}

1. Wang $B, M a Y$, Kong $X$, Ding $X, G u H$, Chu T, et al. NAD(+) administration decreases doxorubicin-induced liver damage of mice by enhancing antioxidation capacity and decreasing DNA damage. Chem Biol Interact. 2014;212:65-71.

2. Mustafa HN, El Awdan SA, Hegazy GA, Abdel Jaleel GA. Prophylactic role of coenzyme Q10 and Cynara scolymus $L$ on doxorubicin-induced toxicity in rats: Biochemical and immunohistochemical study. Indian J Pharmacol. 2015;47(6):649-56

3. Smith LA, Cornelius VR, Plummer CJ, Levitt G, Verrill M, Canney P, et al. Cardiotoxicity of anthracycline agents for the treatment of cancer: Systematic review and meta-analysis of randomised controlled trials. BMC Cancer. 2010;10(1):337.

4. Das J, Ghosh J, Manna P, Sil PC. Taurine suppresses doxorubicin-triggered oxidative stress and cardiac apoptosis in rat via up-regulation of PI3-K/Akt and inhibition of p53, p38-JNK. Biochem Pharmacol. 2011;81(7):891-909.

5. Yang F, Teves SS, Kemp CJ, Henikoff S. Doxorubicin, DNA torsion, and chromatin dynamics. Biochim Biophys Acta. 2014;1845(1):84-9.

6. Wallace KB. Doxorubicin-induced cardiac mitochondrionopathy. Pharmacol Toxicol. 2003;93(3):105-15
7. Yeh ET, Tong AT, Lenihan DJ, Yusuf SW, Swafford J, Champion C, et al. Cardiovascular complications of cancer therapy: diagnosis, pathogenesis, and management. Circulation. 2004;109(25):3122-31.

8. Tiwari P, Mishra BN, Sangwan NS. Phytochemical and pharmacological properties of Gymnema Sylvestre: an important medicinal plant. BioMed Research International. 2014;2014:1-18.

9. Fabio GD, Romanucci V, Marco AD, Zarrelli A. Triterpenoids from Gymnema Sylvestre and their pharmacological activities. Molecules (Basel, Switzerland). 2014;19(8):10956-81.

10. Armando Z, Marina D, Afef L, Rabiaa H, Lucio P. New Triterpenes from Gymnema Sylvestre. Helvetica Chimica Acta. 2013;96(6):1036-45.

11. Benson BB, BekroYA, Mamyrbekova BJA, Coulibaly WK, Ehile EE. Assessment of Sexual Stimulant Potential of Total Flavonoids Extracted from Leaves of Palisota Hirsuta Thunb. K. Schum (Commelinaceae). Europ J of Sci Res. 2008;22(4):533-8.

12. Upaganlawar A, Gandhi C, Balaraman R. Effect of green tea and vitamin E combination in isoproterenol induced myocardial infarction in rats. Plant Foods Hum Nutr. 2009;64(1):75-80.

13. Saeed NM, El-Naga RN, El-Bakly WM, Abdel-Rahman HM, Salah EIDin RA El-Demerdash E. Epigallocatechin-3-gallate pretreatment attenuates doxorubicin-induced cardiotoxicity in rats: A mechanistic study. Biochem Pharmacol. 2015;95(3):145-55.

14. Guerra J, Jesus AD, Santiago BP, Roman FA, Rodriguez E, Crespo MJ. Plasma nitric oxide levels used as an indicator of doxorubicin-induced cardiotoxicity in rats. Hematol J. 2005;5(7):584-8.

15. Lobo RO, Chandrasekhar SBK, Shenoy CK. Bio-tea prevents membrane destabilization during Isoproterenol-induced myocardial injury. Journal of Microscopy and Ultrastructure. 2017;5(3):146-54.

16. Akkiraju SYP, Venkatesh P, Ranjith KK, Suma V, Rojapathi NM. Cardioprotective Effect of Clove Oil in Isoprenaline Induced Myocardial Infarction on Male Wistar Rats Inventi: Ethnopharmacol. 2014;2014(2):1-3.

17. Mukthamba P, Srinivasan K. Dietary fenugreek (Trigonella foenum-graecum) seeds and garlic (Allium sativum) alleviates oxidative stress in experimental myocardial infarction. Food Science and Human Wellness. 2017;6(2):77-87.

18. Zhang XJ, Cao XQ, Zhang CS, Zhao Z. 17ß-estradiol protects against doxorubicininduced cardiotoxicity in male Sprague-Dawley rats by regulating NADPH oxidase and apoptosis genes. Mol Med Rep. 2017;15(5):2695-702.

19. Arozal W, Louisa M, Siswanto S, Soetikno V, Nafrialdi N, et al. Cardioprotection mechanism of mangiferin on doxorubicin-induced rats: Focus on intracellular calcium regulation. Pharm Biol. 2016;54(7):1289-97.

20. Krishnamurthy B, Rani N, Bharti S, Golechha M, Bhatia J, Nag TC, et al. Febuxostat ameliorates doxorubicin-induced cardiotoxicity in rats. Chem Biol Interact. 2015;237:96-103.

21. Kalivendi SV, Kotamraju S, Zhao H, Joseph J, Kalyanaraman B. Doxorubicininduced apoptosis is associated with increased transcription of endothelia nitric-oxide synthase. Effect of antiapoptotic antioxidants and calcium. J Biol Chem. 2001;276(50):47266-76.

22. Anila L, Vijayalakshmi NR. Flavonoids from Emblica officinalis and Mangifera indica-effectiveness for dyslipidemia. J Ethnopharmacol. 2002;79(1):81-7.

23. Menon N, Sparks J, Omoruyi F. Oxidative stress parameters and erythrocyte membrane adenosine triphosphatase activities in streptozotocin-induced diabetic rats administered aqueous preparation of Kalanchoe Pinnata leaves. Pharmacognosy Res. 2016;8(2):85-8.

24. Patel V, Upaganlawar A, Zalawadia R, Balaraman R. Cardioprotective effect of melatonin against isoproterenol induced myocardial infarction in rats: A biochemical, electrocardiographic and histoarchitectural evaluation. Eur J Pharmacol. 2010;644(1-3):160-8.

Article History: Submission Date : 04-04-2018; Revised Date : 28-06-2018; Acceptance Date : 27-07-2018.

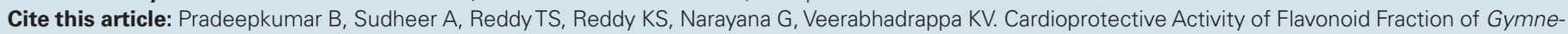
ma Sylvestre Leaves on Doxorubicin Induced Cardiac Damage. JYoung Pharm. 2018;10(4):422-6. 